\title{
DE LA TECNOLOGÍA DE FABRICACIÓN DE TRANSISTORES Y CIRCUITOS INTEGRADOS
}

\section{FABRICATION TECHNOLOGY OF TRANSISTORS AND INTEGRATED CIRCUITS}

Arturo Pérez París: Universidad de Alcalá de Henares. Madrid (España). arturo.perez@mixmail.com

\section{CURRÍCULUM VITAE}

Escuela Politécnica de la Universidad de Alcalá de Henares. Ingeniero electrónico y literato. Destacan sus estudios sobre aplicaciones eléctricas y motricidad sobre los que ha publicado varios artículos científicos.

\section{RESUMEN}

Hace un tiempo se pensaba que la tecnología basada en semiconductores era de procedencia extraterrestre y que empezó a desarrollarse a partir de los sucesos de Roswell. A lo largo de este artículo se pretende explicar la procedencia, principios y procesos de fabricación de los transistores, base de los circuitos integrados o chips. Sus características han permitido que se desarrollen con gran rapidez los componentes en estado sólido, o semiconductores, frente a las válvulas de vacío que les precedieron. 


\section{PALABRAS CLAVE}

Semiconductores - Transistores - Circuitos integrados

\section{ABSTRACT}

Some time ago it was thought that semiconductor-based technology was extraterrestrial origin and that began to develop from the events of Roswell. Throughout this article is to explain the origin, principles and processes for manufacturing transistors based integrated circuits, or chips. Its characteristics have allowed to develop rapidly in the solid state components, or semiconductors, compared to vacuum tubes that preceded them.

\section{KEY WORDS}

Semiconductors - Transistors - ICs

\section{ÍNDICE}

1. Introducción

2. Fabricación de transistores

3. Microelectrónica

4. Circuitos monolíticos

5. Circuitos peliculares

6. Conclusión 


\section{TEXTO:}

\section{Introducción}

En números anteriores se presentó la implementación semiprofesional de placas de circuito impreso. En esta ocasión, hemos creído pertinente dar a conocer el proceso de fabricación de algunos dispositivos utilizados en los circuitos electrónicos así como sus propiedades. El trabajo, dada su extensión, lo hemos dividido en varias partes, como viene siendo habitual. En la primera entrega tratamos de la fabricación de resistencias, condensadores, bobinas y núcleos comúnmente utilizados, transformadores y relés, los llamados componentes electrónicos pasivos. En el anterior artículo hicimos una breve y somera presentación de los semiconductores y sus más frecuentes aplicaciones.

En el presente artículo se pretenden describir las diferentes técnicas de construcción de transistores y de circuitos integrados. Va a estar dedicado a los principales métodos de fabricación de estos componentes. En los párrafos correspondientes a la fabricación de transistores, se explicarán las técnicas aplicadas para la obtención de dispositivos: planar, epitaxial, mesa semiplanar, homotaxial y aleación-difusión. También se tratará la construcción, funcionamiento y características de los transistores de efecto de campo (FET). En los párrafos dedicados al proceso de fabricación de circuitos integrados, se estudiarán los tipos fundamentales de esta clase de dispositivos: los circuitos integrados monolíticos, los circuitos integrados peliculares y los circuitos integrados híbridos.

\section{Fabricación de transistores}

En la fabricación de transistores, la técnica planar (su nombre se debe a que todas las operaciones tienen lugar sobre el mismo plano del cristal que sirve de soporte), se basa en la utilización de una plaquita de silicio, tipo P o N, que constituirá el colector. El proceso será tal y como sigue: 
- Por uno de los lados de la plaquita se deposita una capa de óxido de silicio, practicándose mediante técnicas fotoquímicas una abertura o ventana.

- A través de la abertura practicada, se difunde el material donador o aceptor, formándose la base del transistor.

- A continuación, se procede a una nueva deposición de óxido de silicio, sobre la cual, mediante la misma técnica (técnica fotoquímica), se practica una ventana menor que la anterior, en la cual se difundirá el emisor.

- Una vez completadas las operaciones de difusión (de base y emisor), la ventana practicada se recubre con una nueva capa de óxido de silicio, sobre la que se practicarán nuevas ventanas para la colocación de los contactos de emisor y de base. El colector se conecta a la parte inferior del cristal.

- Por último, todo el conjunto se vuelve a recubrir con una capa de óxido de silicio, que protege al dispositivo contra los agentes externos.

La figura, que a continuación se muestra, enseña el proceso de fabricación de un transistor planar hasta que se han formado el colector, la base y el emisor. 


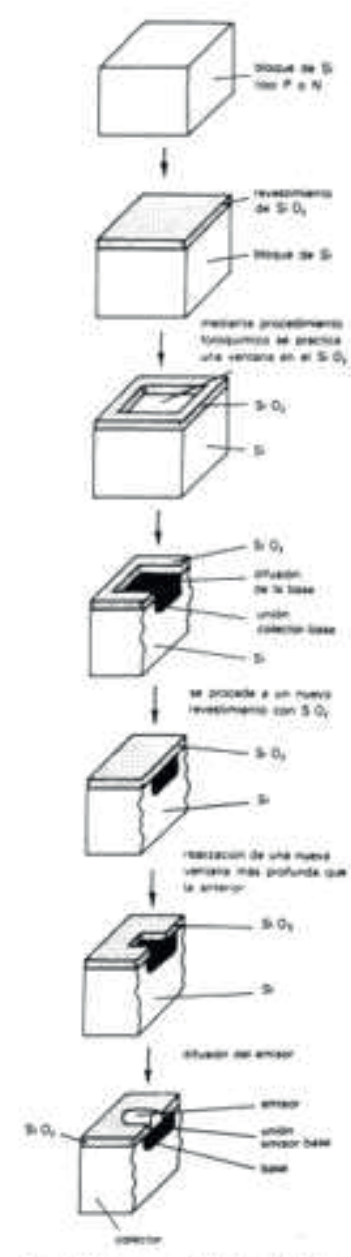

Los transistores fabricados con esta técnica presentan unas corrientes inversas muy pequeñas, frecuencias de transición máximas de unos $100 \mathrm{MHz}$ (recuérdese que la frecuencia de transición viene definida por el producto del ancho de banda por la amplificación), tensiones de unos $100 \mathrm{~V}$, y una corriente máxima de unos 10 A. Estos transistores se pueden obtener en versión PNP o NPN. Por último, cabe decir que ésta es la técnica más empleada en la fabricación de circuitos integrados.

Otra técnica de fabricación de transistores es la epitaxial. Los transistores producidos con esta técnica se denominan también transistores mesa. La técnica epitaxial consiste en hacer crecer un material semiconductor en estado de cristal sobre otro 
material semiconductor que, a su vez, se halla también en estado de cristal. Esta técnica a grandes rasgos seguirá el siguiente proceso:

- Sobre una capa de silicio fuertemente impurificada (por ejemplo N) y, por consiguiente, de baja resistencia, que constituirá el colector, se hace crecer una fina capa de silicio, poco impurificada y, por tanto, de elevada resistencia, que constituirá la base.

- Posteriormente, se recubre la base con una capa de óxido de silicio, sobre la que, por procedimientos fotoquímicos, se practicará una ventana a través de la cual, mediante difusión, se obtendrá la capa que constituirá el emisor.

- Para finalizar el proceso, al igual que en el proceso planar, se practicarán las ventanas y recubrimientos con óxido de silicio necesarios con el fin de obtener las conexiones exteriores de base, emisor y colector.

A continuación, se muestra el proceso de fabricación de un transistor epitaxial hasta que se han formado el emisor, la base y el colector. 


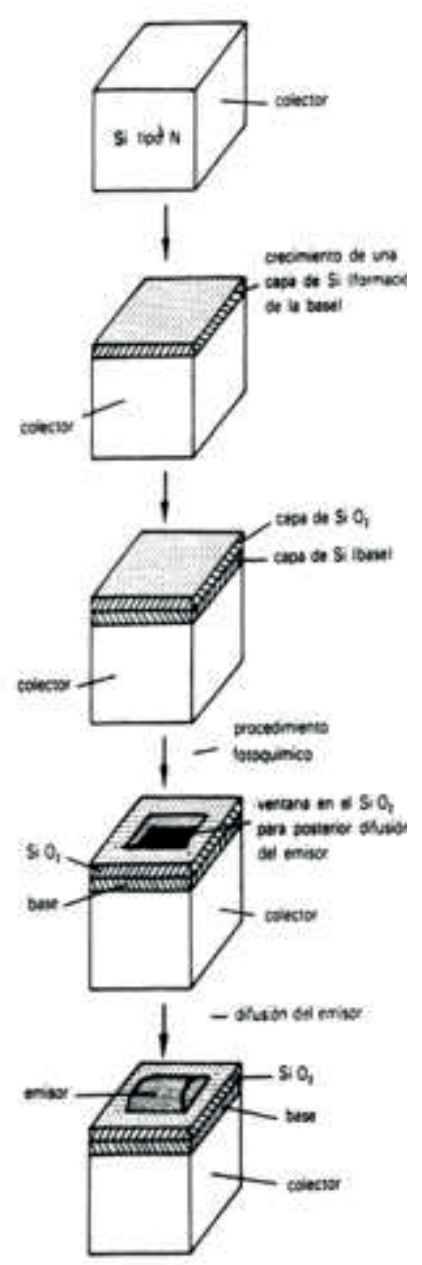

Estos transistores resultan indicados para su utilización en aplicaciones de baja frecuencia de potencia. La frecuencia máxima de transición es de unos $5 \mathrm{MHz}$, soportando tensiones de hasta unos $200 \mathrm{~V}$.

La tercera técnica comentada es la de mesa-semiplanar. Esta técnica consiste en obtener la unión emisor-base por medio de tecnología planar, y la unión basecolector por medio de tecnología mesa. El proceso a seguir será el que se expone a continuación:

- Sobre una plaquita de silicio fuertemente impurificada, se procede a la difusión de una capa de silicio poco impurificada por la cara superior y la inferior.

Conviene señalar que el material que permanece entre las dos capas difundidas no forma la base, sino el colector. 
- Se recubre toda la plaquita con óxido de silicio.

- Se procede a eliminar por completo la capa difundida interior.

- Posteriormente, mediante la técnica planar ya conocida, se procede a la formación del emisor sobre la capa superior (que será la base).

Los transistores obtenidos mediante este procedimiento poseen frecuencias de transición máximas del orden de $50 \mathrm{MHz}$, constituyendo su principal ventaja el que pueden trabajar a tensiones relativamente elevadas (de hasta $1500 \mathrm{~V}$ ). Mediante esta técnica sólo se obtienen transistores NPN.

La cuarta técnica a comentar es la homotaxial. Los transistores obtenidos mediante esta técnica se denominan también de difusión única. Su proceso de fabricación es:

- A partir de una plaquita de semiconductor tipo P, se procede a la difusión de semiconductor tipo $\mathrm{N}$ (donador) por las caras superior e inferior de la plaquita inicial. Mediante este procedimiento se obtienen el colector y el emisor. La plaquita inicial de tipo P constituirá la base.

Los transistores obtenidos por este proceso resultan adecuados para su utilización con corrientes elevadas. Su frecuencia de transición máxima se sitúa alrededor de 1 MHz y soportan tensiones de hasta unos $100 \mathrm{~V}$. Mediante esta técnica sólo se fabrican transistores NPN.

La siguiente técnica es la de aleación y difusión, también denominada técnica de aleación difusa. Consiste en obtener la unión base - colector por aleación, y la unión base - emisor por difusión. El proceso a seguir para esta técnica es:

- Sobre una plaquita de material semiconductor (germanio tipo P, por ejemplo), se deposita un pequeño dado de material donador (antimonio, por ejemplo) que, sometido a un proceso de fusión, se aleará con el semiconductor de la plaquita inicial, formando una unión NP que constituirá la unión colector - base. 
- Posteriormente, y sobre una parte de la zona de aleación, se deposita, por el procedimiento de difusión, una pequeña capa de material aceptor, que formará el emisor.

Este proceso está esquematizado en la figura siguiente:

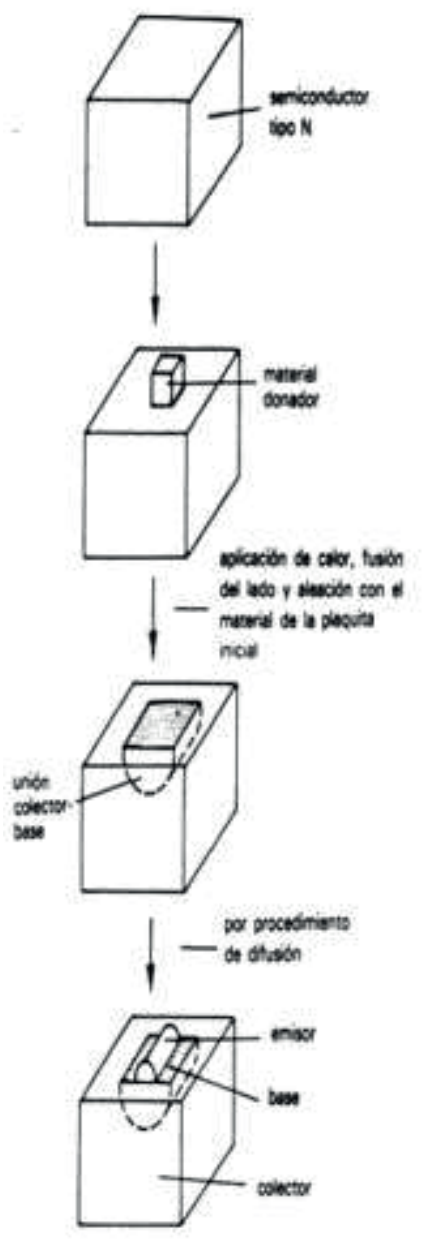

- Completarán el proceso descrito (que es de fabricación de un transistor PNP) las operaciones pertinentes para el aislamiento del conjunto y la colocación de los contactos de emisor y base. 


\section{Microelectrónica}

Con el descubrimiento del transistor se dio un impulso a la electrónica, lo cual no sólo tuvo enorme importancia por la disminución del tamaño y la potencia consumida por los circuitos, sino también por las nuevas técnicas e investigaciones que a partir de él, se desarrollaron. Fruto, en buena medida, de esas investigaciones son los circuitos integrados que, de una manera muy general, pueden definirse como pequeños cristales que contienen elementos activos $y$ pasivos con sus interconexiones. Los circuitos integrados han supuesto un importante avance en la configuración de los sistemas electrónicos sobre todo por la aparición de nuevos conceptos; entre ellos cabe señalar:

- La miniaturización de los equipos.

- La mayor fiabilidad de los diseños, originada por los trabajos de investigación desarrollados en torno a ellos.

- El menor coste de la fabricación en grandes series.

- La posibilidad de trabajar con frecuencias más elevadas al eliminar conductores, etc.

El variado conjunto de dispositivos y técnicas desarrollados con el afán de reducir las dimensiones de los circuitos, se suele denominar microelectrónica, palabra utilizada muchas veces en el mismo sentido que circuito integrado, pero que comprende un campo más amplio. La microelectrónica puede subdividirse en:

-Circuitos integrados monolíticos

-Circuitos integrados peliculares:

De película delgada

De película gruesa

-Circuitos multiplaca 
-Circuitos híbridos

\section{Circuitos monolíticos}

Los circuitos integrados monolíticos se construyen sobre una plaquita de silicio, denominada sustrato, generalmente de tipo P. Se configura como una unidad inseparable que forma una estructura única, cuyos componentes van formándose simultáneamente, y que no puede ser dividida sin destruir de forma irreversible su función eléctrica. El proceso de fabricación está basado en la técnica planar, vista anteriormente, pudiéndose distinguir en él varios apartados: la preparación de las máscaras fotográficas, la elaboración del circuito y, por fin, el encapsulado y verificación.

En primer lugar, una vez calculados los valores y ajustado el circuito en su funcionamiento o las limitaciones propias de esta técnica, se procede a la disposición de los elementos sobre el cristal. Una vez conformado el conjunto, se desarrollan las máscaras fotográficas que, con sus correspondientes aberturas, irán dando lugar a las sucesivas partes del circuito en procesos posteriores. Cada una de estas máscaras se corresponderá con una fase de fabricación en la que se producirán varios elementos a la vez (por ejemplo, bases y resistencias, emisores y capacidades, etc.). Las máscaras se diseñan inicialmente a escala 500:1 y, más tarde, son reducidas al tamaño real, pasando a disponerse conjuntamente de un número de ellas igual al número de circuitos que pueden obtenerse de una oblea de silicio (que llega a ser de varias centenas). Esto se repite para cada fase del proceso. 


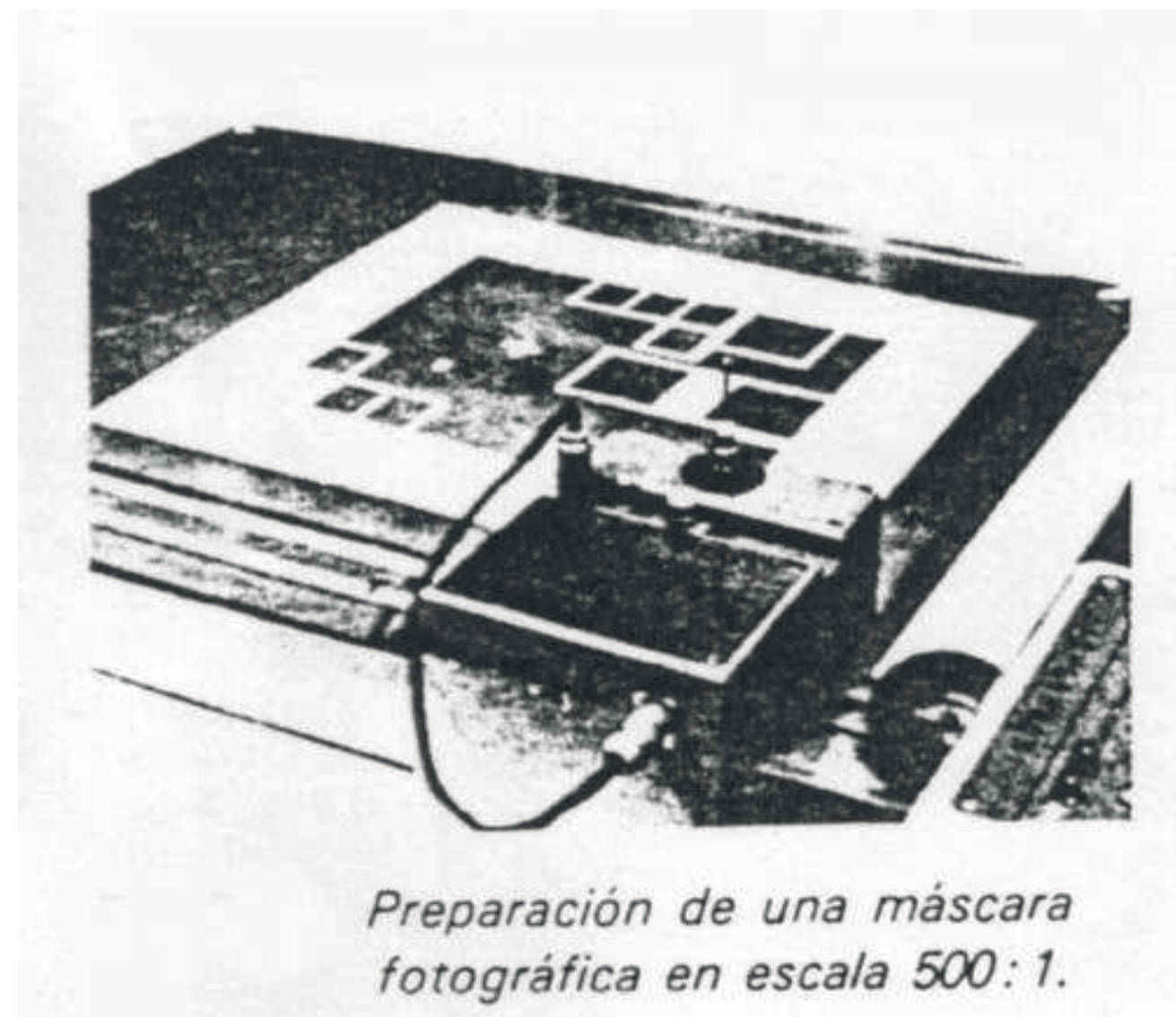

En la realización del circuito propiamente dicho, intervienen varios procesos bien diferentes. Los principales son:

- Preparación y purificación del silicio.

- Crecimiento de la capa epitaxial.

- Oxidación.

- Fotolitografiado.

- Difusión.

- Conexionado (deposición metálica).

El correcto funcionamiento de estos circuitos depende del riguroso control que se realice sobre el número de impurezas que se introduzcan en el silicio. Es, por lo tanto, de suma trascendencia asegurar que el cristal utilizado como sustrato sea de la mayor pureza en su composición y de la mayor regularidad en la formación de su 
estructura cristalina. Para obtener la adecuada pureza se somete el silicio a una serie de procesos químicos y físicos a elevadas temperaturas, de los cuales, tras sucesivas mezclas, fusiones, destilaciones y descomposiciones, resulta un silicio con una pureza del orden de un átomo de impureza por cada 1010 átomos de silicio. Para conseguir una estructura cristalina totalmente regular, se realiza el alargamiento controlado del cristal con un dispositivo, tal como se muestra:

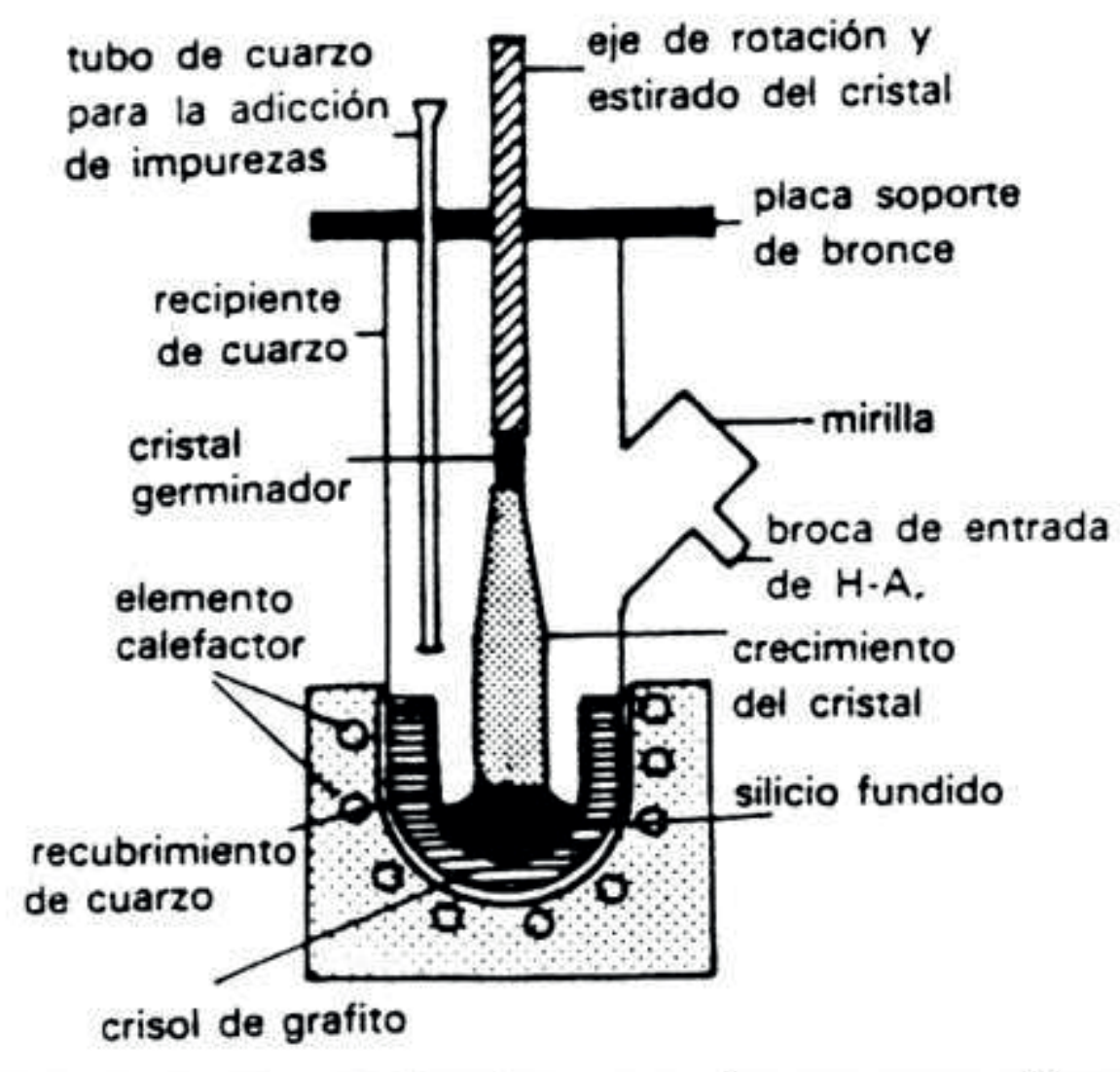

Partiendo del silicio purificado fundido en el crisol, se le pone en contacto un cristal tipo (germinador), que se hace girar a la vez que se retira lentamente; el silicio va creciendo adherido al germinador y adoptando una estructura cristalina sumamente regular. Una vez realizado este proceso, se procede a difundir una muy controlada cantidad de impurezas donadoras o aceptoras (generalmente aceptoras), con lo cual se puede pasar a cortar el silicio en discos que, una vez pulidos, constituyen los sustratos listos para la formación del circuito. 
El crecimiento de la capa epitaxial consiste en hacer crecer una película delgada de silicio N o P sobre el sustrato preparado anteriormente. La película será de muy baja resistividad frente a la resistividad de la oblea y de signo contrario a ella. El crecimiento de la capa epitaxial se obtiene introduciendo las obleas en un ambiente de gas de silicio adecuadamente dopado a elevada temperatura. La resistividad de la película crecida depende de la concentración de impurezas en el gas; y el espesor de la capa, del tiempo de exposición:

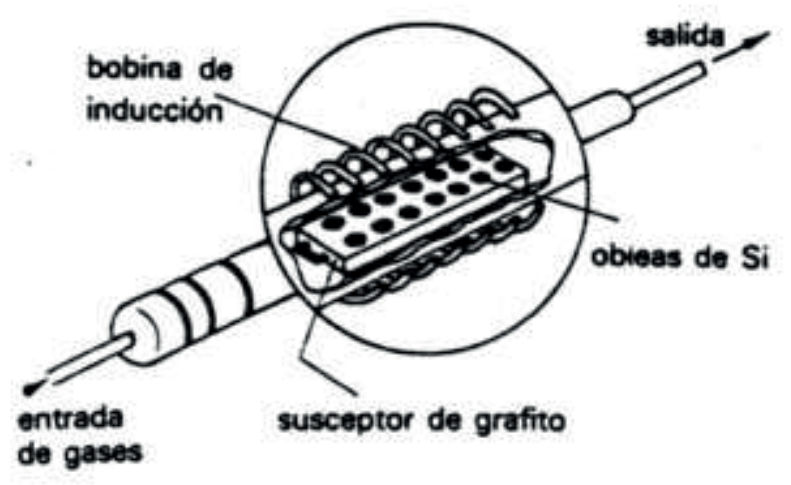

A

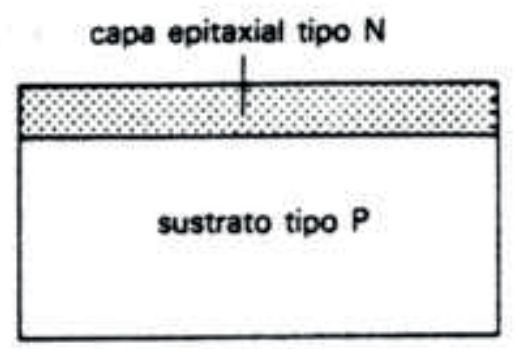

B

A, sistema para el crecimiento de la capa epitaxial; B, representación del substrato de silicio $P$ con la capa epitaxial ya crecida. 
A lo largo del proceso, la oblea de silicio es sometida repetidamente a procesos de oxidación. La finalidad de estas oxidaciones consiste en controlar las zonas donde han de producirse las difusiones de impurezas; el óxido de silicio forma una barrera, a través de la cual no puede difundirse el gas dopado que en cada momento se utiliza. De este modo, abriendo las ventanas necesarias en el óxido de silicio, con ayuda de las máscaras fotográficas, se consigue determinar las zonas donde difundir. La oxidación se consigue calentando el sustrato con la capa epitaxial hasta unos 1000 ${ }^{\circ} \mathrm{C}$ y sometiéndolo a un chorro de oxígeno o vapor. La temperatura y el tiempo de exposición determinan el espesor de la capa oxidada:

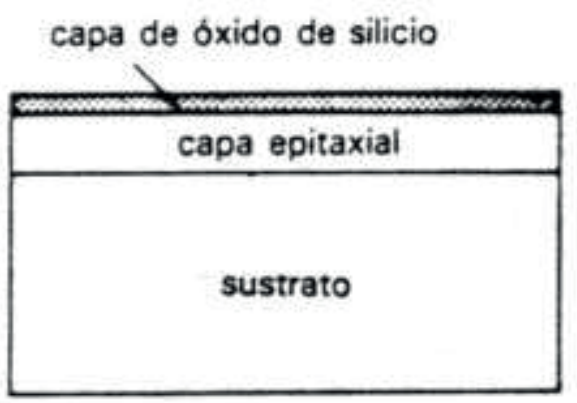

En esta parte del proceso, como ya se ha señalado con anterioridad, se determinan las zonas donde deben producirse las difusiones. Sobre el óxido de silicio se aplica una emulsión fotosensible que, con la correspondiente máscara superpuesta, es sometida a radiaciones ultravioleta. Las zonas de emulsión situadas bajo partes transparentes de la fotomáscara se polimerizan; en el resto de las zonas queda la emulsión blanda, siendo eliminada junto con el óxido que hay debajo de ellas. Así, el disco de silicio queda expuesto en esas partes a las difusiones pertinentes: 


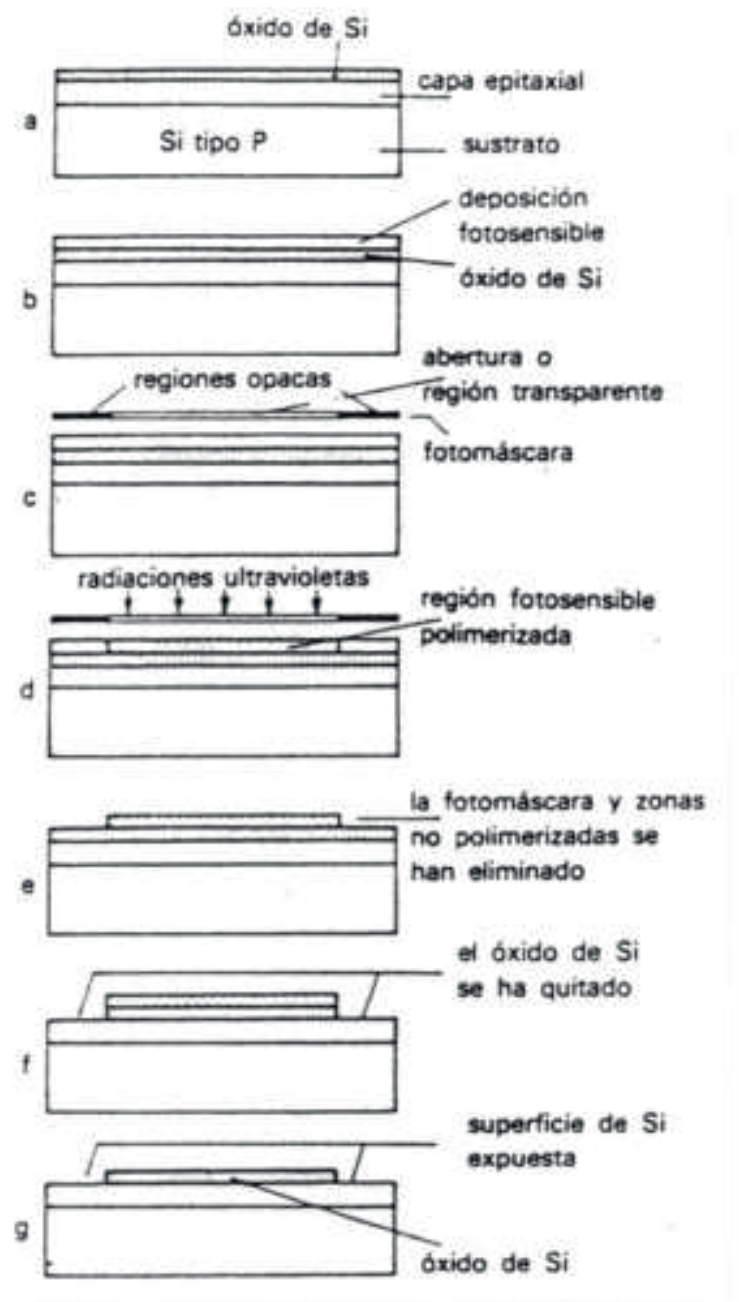

La difusión es, quizás, la parte más importante en la fabricación de los circuitos integrados monolíticos. Consiste en introducir el disco fotolitografiado en una atmósfera, con una exacta densidad de átomos de impureza, a una temperatura de unos $1200^{\circ} \mathrm{C}$. La introducción de átomos de impureza, es muy lenta $(2,5 \mathrm{~m} \mathrm{~m}$ por hora), lo que permite regularla con toda precisión: 


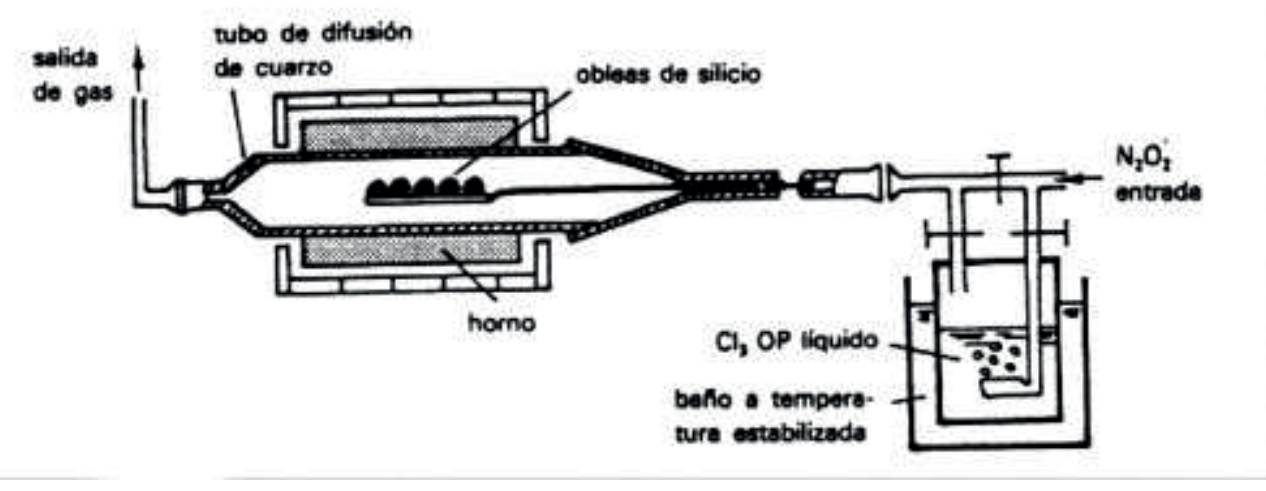

Normalmente se desarrolla en dos procesos diferentes: la sedimentación y la difusión. La sedimentación se produce en la etapa comentada en el párrafo anterior, y la difusión se logra introduciendo de nuevo los discos en otra estufa a temperatura más elevada, para que las impurezas sedimentadas se desplacen o difundan en el silicio:

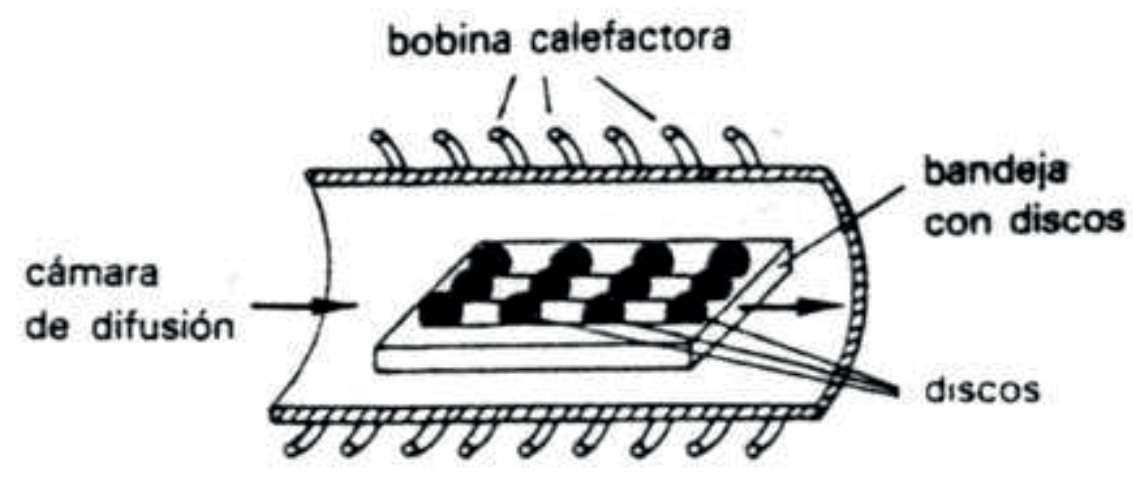

Sobre una capa difundida con determinada impureza pueden volverse a difundir impurezas de signo contrario con una concentración más elevada, formándose así sucesivas uniones NP, que dan lugar a los diversos componentes: 


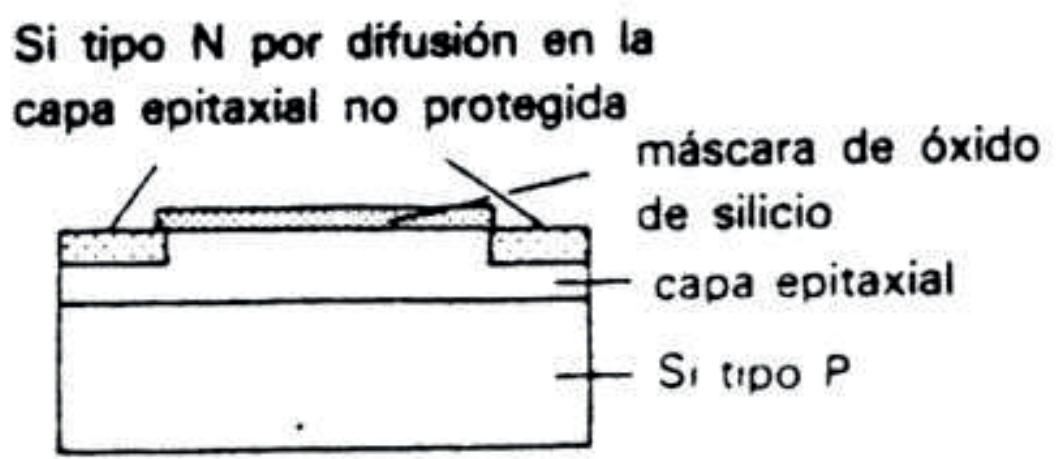

Una vez fabricados los diversos componentes del circuito, se conectan entre sí. Para esto, se recubre la totalidad del circuito con una delgada capa de aluminio, que es atacada y eliminada con ayuda de un nuevo proceso de fotograbación. Así, el circuito queda ya montado y listo para una primera comprobación y su posterior encapsulamiento:

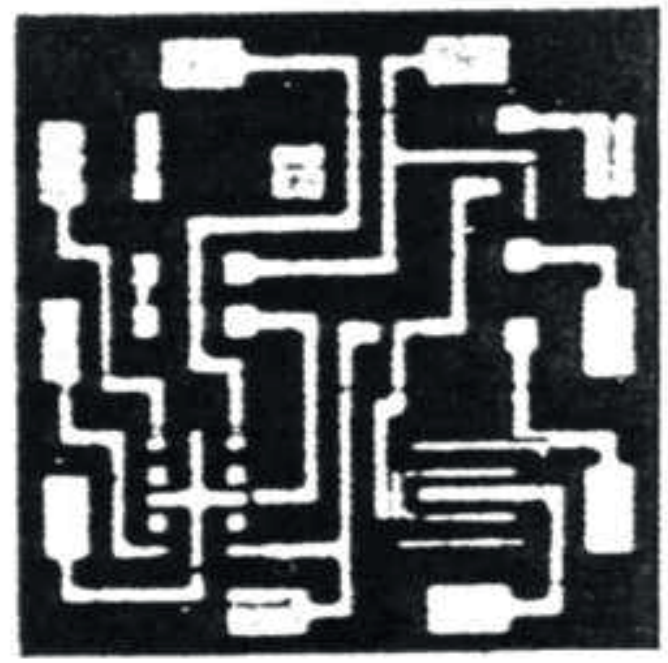

metalización

Metalización de un circuito integrado. 
Una vez producidos los circuitos sobre la oblea, se comprueban superficialmente. La misma máquina que los verifica mancha de tinta aquéllos que deben desecharse. Más tarde, la oblea se raya con una fina punta de diamante en las dos direcciones, por los espacios existentes entre circuito y circuito. Después se somete a una pequeña presión que la descompone en pequeños cuadrados, que contienen los circuitos individuales:

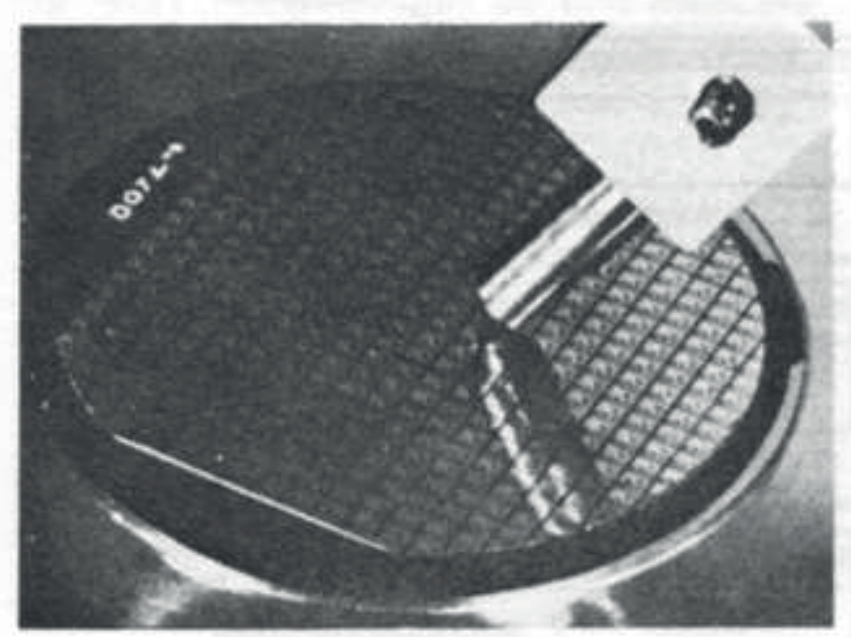

Estos pequeños cristales son colocados en la cápsula adecuada sobre una base, a la cual van fijos:

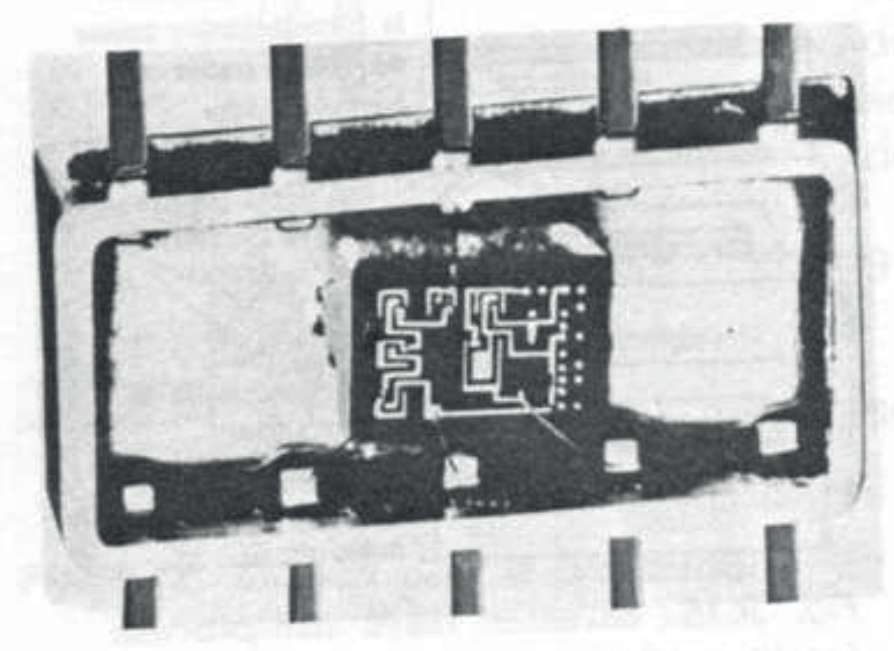


Más tarde, se sueldan los terminales mediante el sistema descrito en la figura siguiente, denominado unión por esfera:

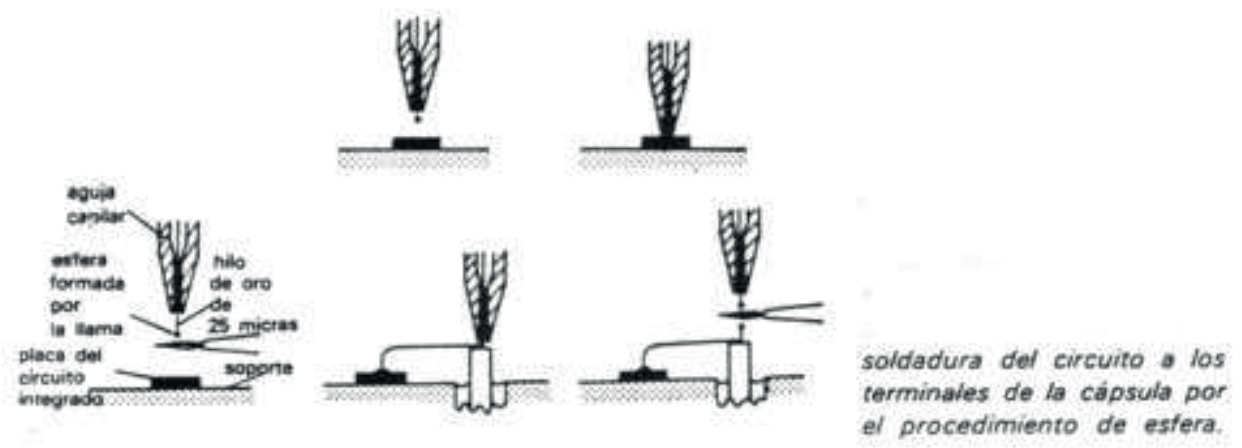

Una vez soldado el circuito, se cierra herméticamente la cápsula, procediéndose, por fin, a verificar rigurosamente las funciones que el circuito debe cumplir. A continuación, se representa completa la secuencia de operaciones estudiadas en apartados anteriores, para la formación de los circuitos integrados monolíticos:

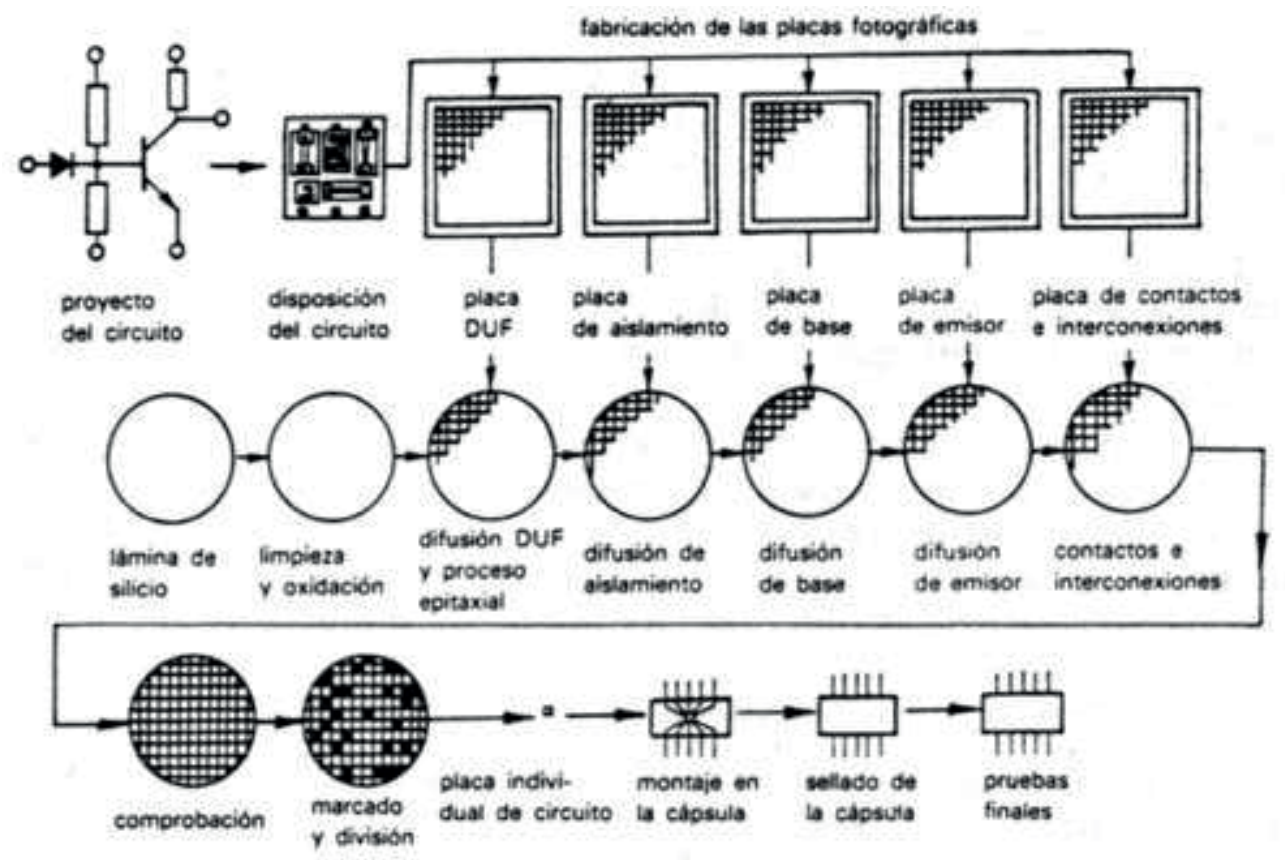

Proceso completo para la fabricación de un circuito integrado monolitico. 
Puesto que todos los elementos se forman sobre un mismo sustrato conductor, es preciso separarlos previamente, de modo que entre ellos sólo existan las conexiones aplicadas con el metalizado. El aislamiento se suele realizar con dos técnicas: por diodos y por oxidación. El aislamiento por diodos consiste en formar pequeñas islas de superficie suficiente como para contener el elemento correspondiente. Esto se logra mediante la difusión, por una serie de ventanas formadas en el óxido aplicado a la capa epitaxial, de impurezas del mismo tipo que el sustrato. Estas impurezas se hacen penetrar hasta atravesar la zona epitaxial. Queda, así, entre las islas una serie de diodos que las separan eléctricamente:

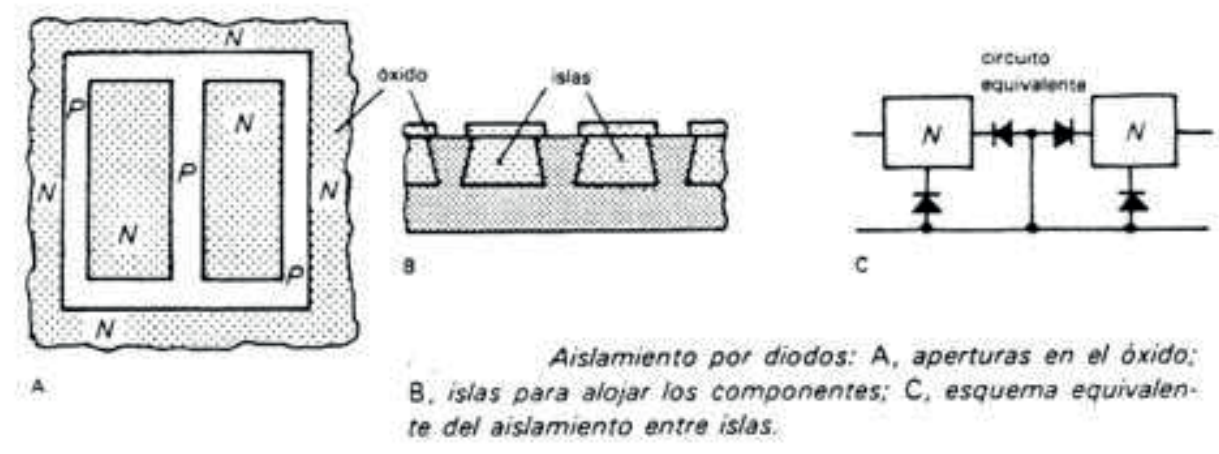

Con el sistema de oxidación no es preciso formar la zona epitaxial. Sobre una lámina de silicio se practica, mediante ataque químico, una serie de grietas con ayuda de la oxidación y el fotolitografiado. Cuando las grietas tienen profundidad suficiente, se vuelve a oxidar el conjunto y, sobre él, se hace crecer una nueva capa de silicio, que más tarde es invertido y rebajado. En las grietas se alojarán con posterioridad los componentes: 

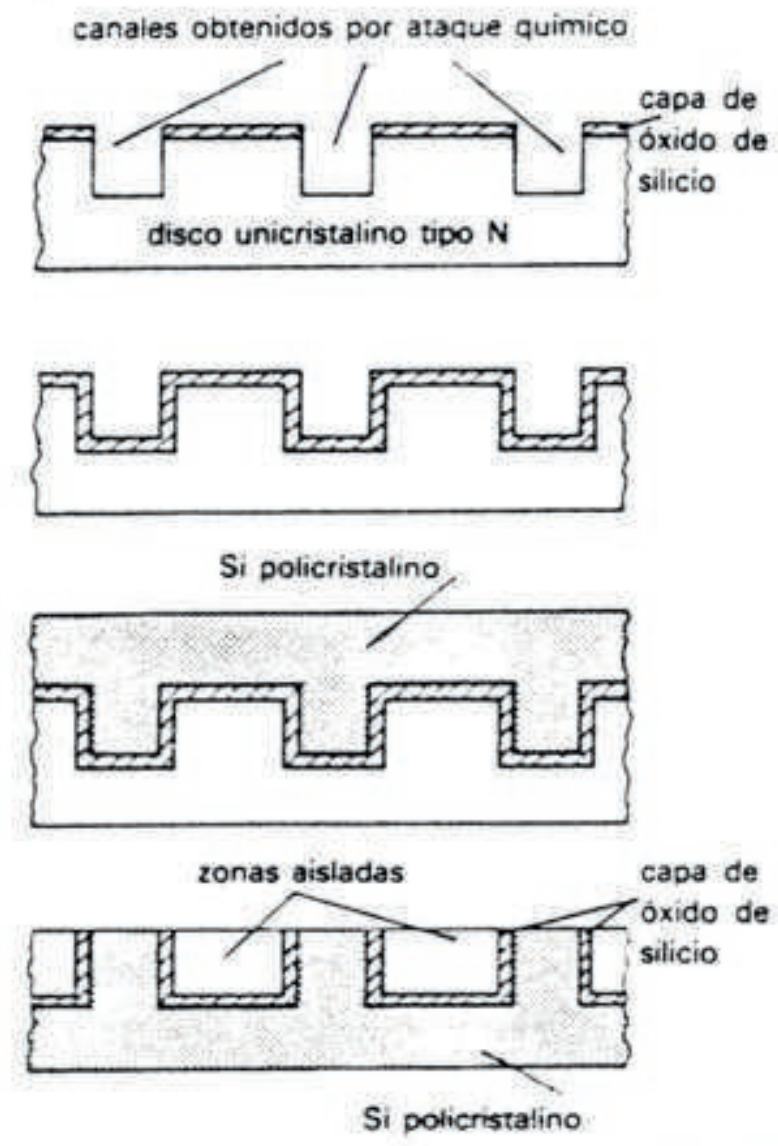

Aislamiento por oxidación.

El silicio es un material cuya resistividad depende de las impurezas que se difunden en él. En esto se basa precisamente la formación de resistencias integradas. Como la profundidad y concentración de las impurezas por difundir vienen fijadas por los transistores que se construyen, la producción de las resistencias está siempre ligada a la de los transistores. El valor de éstas sólo puede regularse variando la superficie por difundir: 


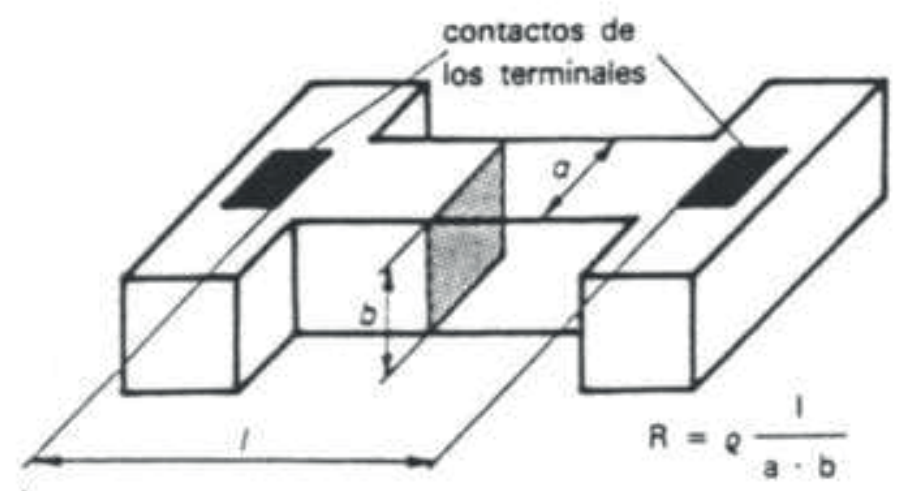

A

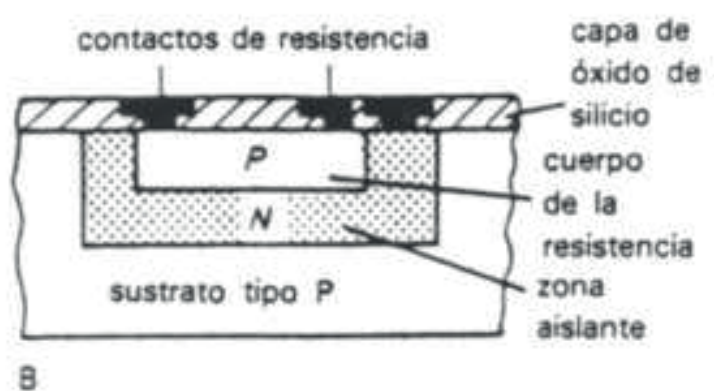

A. perspectiva del semicon-

ductor que forma la resistencia inte-

grada; B, estructura de la resistencia

integrada.

Las resistencias de valores normales se realizan a la vez que las bases de los transistores, que requieren una pequeña concentración de impurezas, lográndose así valores entre 20 ohmios y 30 kilo-ohmios. Las de pequeño valor, hasta unos 2 ohmios, se producen a la vez que los emisores, realizados con una mayor densidad en la difusión. Hasta el presente, no se ha logrado una tolerancia en la producción menor del $5 \%$ para las resistencias; sin embargo, se consiguen errores de hasta un 1 \% en la relación de valores entre resistencias fabricadas a la vez. Esto hace que en la actualidad se tienda a calcular los circuitos, no por los valores absolutos de las resistencias, sino por las relaciones entre ellos. 
Las capacidades en los circuitos integrados pueden conseguirse por varios métodos. Los más usuales son: el tipo unión NP y el tipo MOS. Las capacidades por unión NP se forman usando la propiedad aislante de la barrera de unión polarizada de forma inversa para conseguir el dieléctrico. Las armaduras son originadas por las zonas semiconductoras:

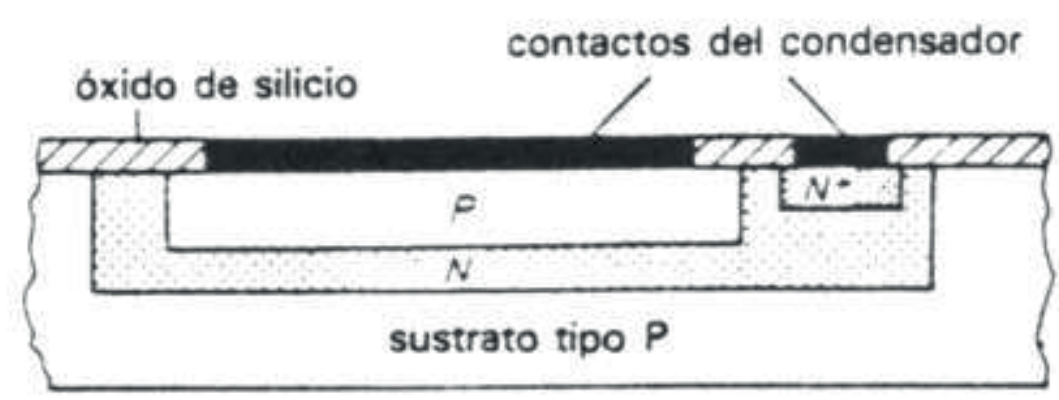

Como las resistencias, los condensadores se forman simultáneamente a los transistores. Por esto, sólo puede actuarse sobre la superficie de la zona difundida y sobre la tensión inversa, aplicada a la unión por variar la capacidad. El condensador de tipo MOS se forma a la vez que el emisor de un transistor, dopando fuertemente una zona que será la primera placa conductora. El dieléctrico es una capa de óxido de silicio y la otra placa conductora la constituye el mismo metal que produce el conexionado final. Este método simplifica el proceso logrando capacidades mayores y con menos corriente de fuga:

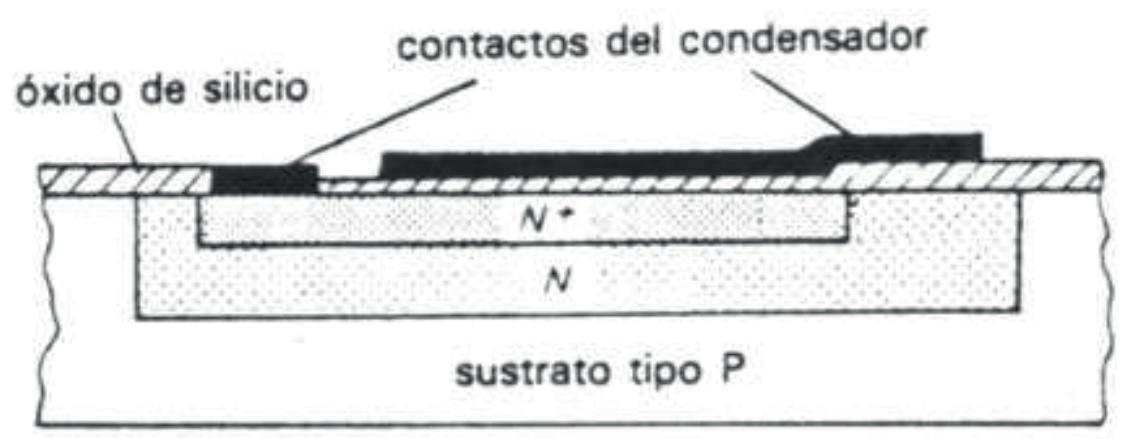


Los transistores bipolares o de unión se forman de modo similar a la técnica planar. Una vez formada la isla, se difunde la base con débil concentración. Sobre la base, se difunde el emisor con gran densidad de impurezas. El colector, también fuertemente dopado, se forma a la vez que el emisor, sobre la isla primitiva:

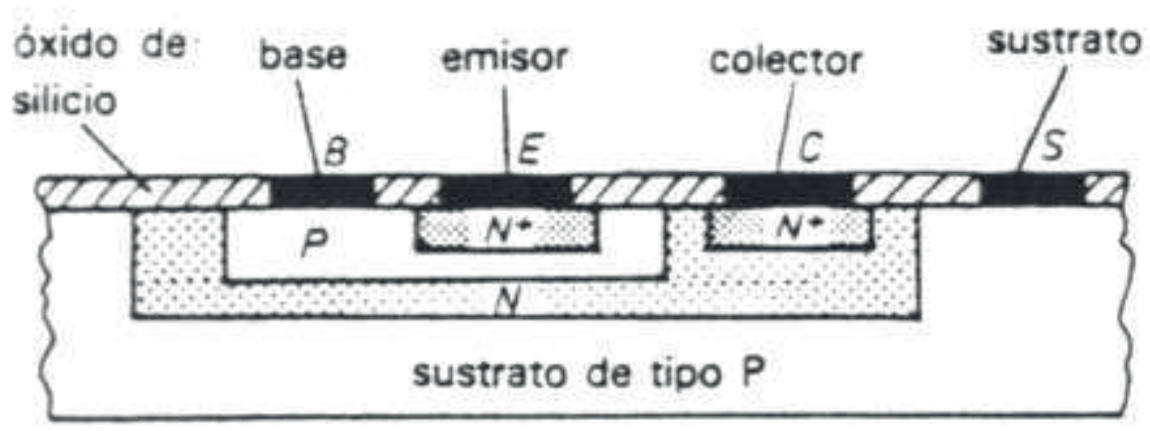

El problema mayor de estos transistores reside en que la corriente de colector ha de circular horizontalmente a lo largo de una estrecha región, lo cual origina una resistencia adicional. Para evitar esta dificultad, se suele difundir en el sustrato, previamente al crecimiento epitaxial, una zona $\mathrm{N}$ de baja resistividad, facilitándose de este modo el camino a la corriente. Esta técnica se denomina DUF, del inglés Diffusion Under The Epitaxial Film (difusión bajo la capa epitaxial):

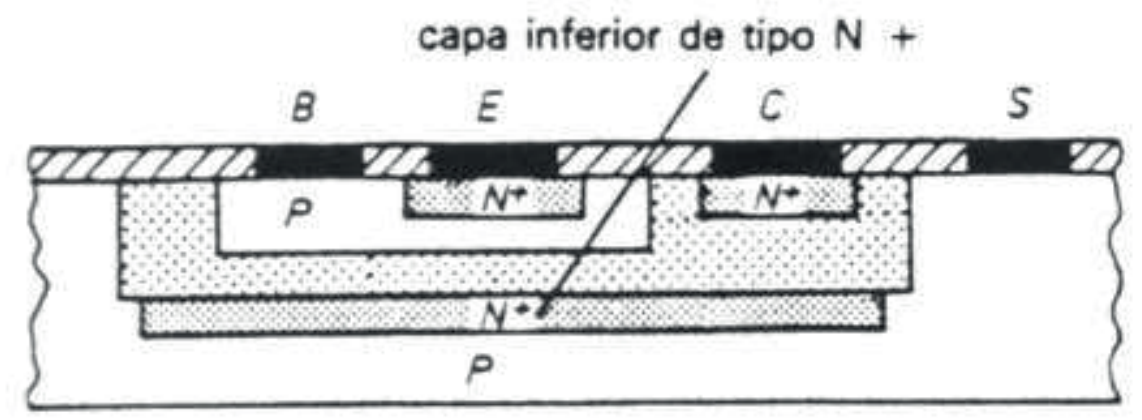

Los diodos se obtienen también dependiendo de la profundidad y concentración que se determine para los transistores. En muchas ocasiones se utilizan incluso transistores adecuadamente conexionados para formar el diodo correspondiente. En 
la figura siguiente pueden verse las disposiciones más utilizadas para obtener diodos:

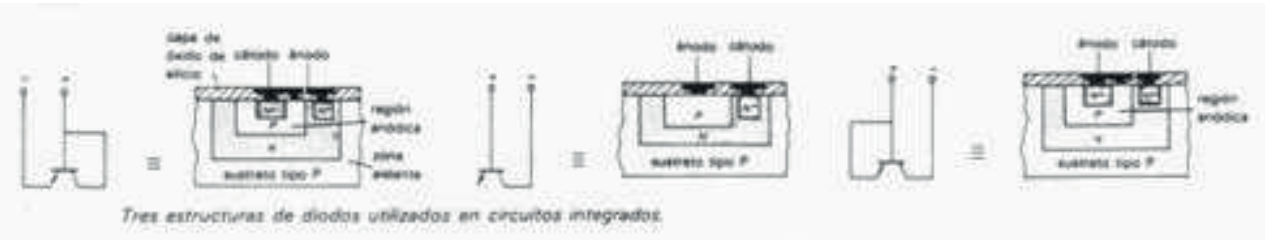

Los transistores de efecto de campo suelen sustituir, en muchas ocasiones, a los de unión o BJT, por reunir las ventajas de una mayor simplicidad en la producción y una menor superficie. También se utiliza, en muchas ocasiones, transistores MOS para suplir resistencias, sobre todo, porque con ellos se consiguen valores mayores de $30 \mathrm{~K}$ en superficies menores. Las figuras, que a continuación se muestran, nos enseñan un transistor MOS en utilización normal, usado como resistencia, y la comparación entre los resultados obtenidos para un circuito simple, usando técnica bipolar y técnica MOS. Obsérvese, en esta última, la diferencia de superficie necesaria:
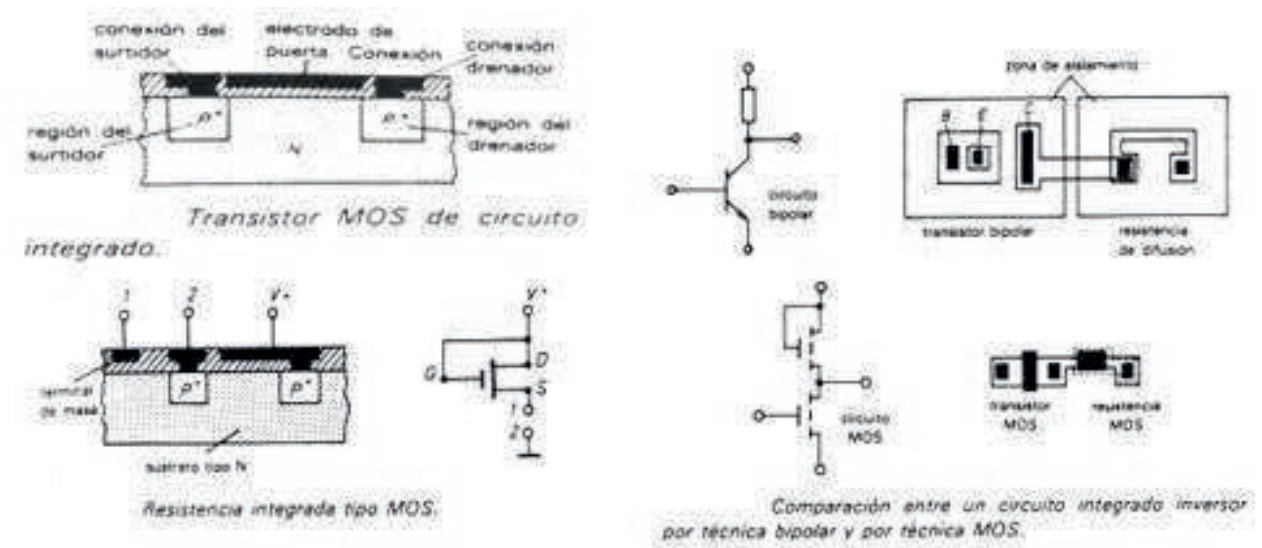

A continuación, se expone gráficamente, en vistas de corte y planta, un ejemplo ilustrativo del proceso de formación de un circuito integrado completo: 


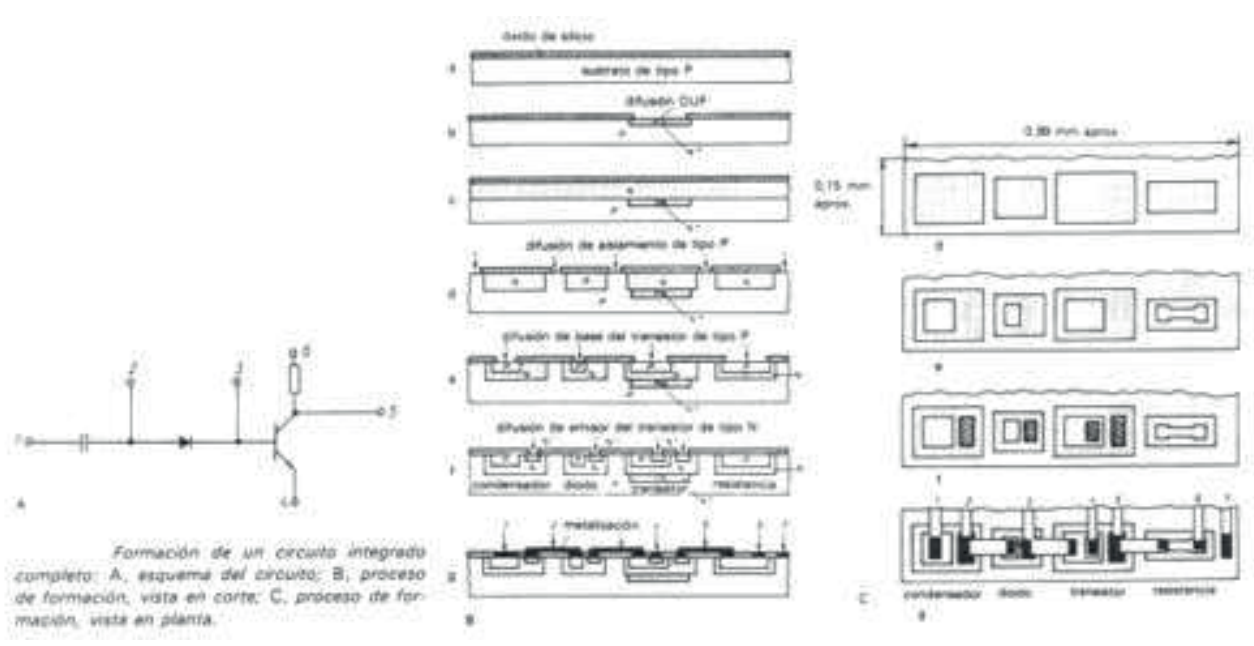

\section{Circuitos peliculares}

Los circuitos integrados peliculares, en muchas ocasiones denominados comúnmente circuitos híbridos, se desarrollan para salvar las limitaciones que la técnica planar impone a los integrados monolíticos: una de estas limitaciones se refiere a las dificultades para obtener resistencias y condensadores de pequeñas tolerancias y elevados valores; otra a la producción de series de circuitos relativamente reducidas que, fabricadas en versiones monolíticas, tendrían precios prohibitivos. La técnica de circuitos integrados peliculares permite la realización, en un encapsulado simple, de combinaciones extremadamente complejas de semiconductores.

Los circuitos integrados de película delgada (thin-film) son circuitos construidos sobre un substrato de cerámica o de vidrio, en los que los elementos pasivos y las interconexiones de los distintos elementos se obtienen por técnicas de evaporación al vacío sobre el substrato, y los elementos activos son montados y soldados sobre éste como unidades independientes: 


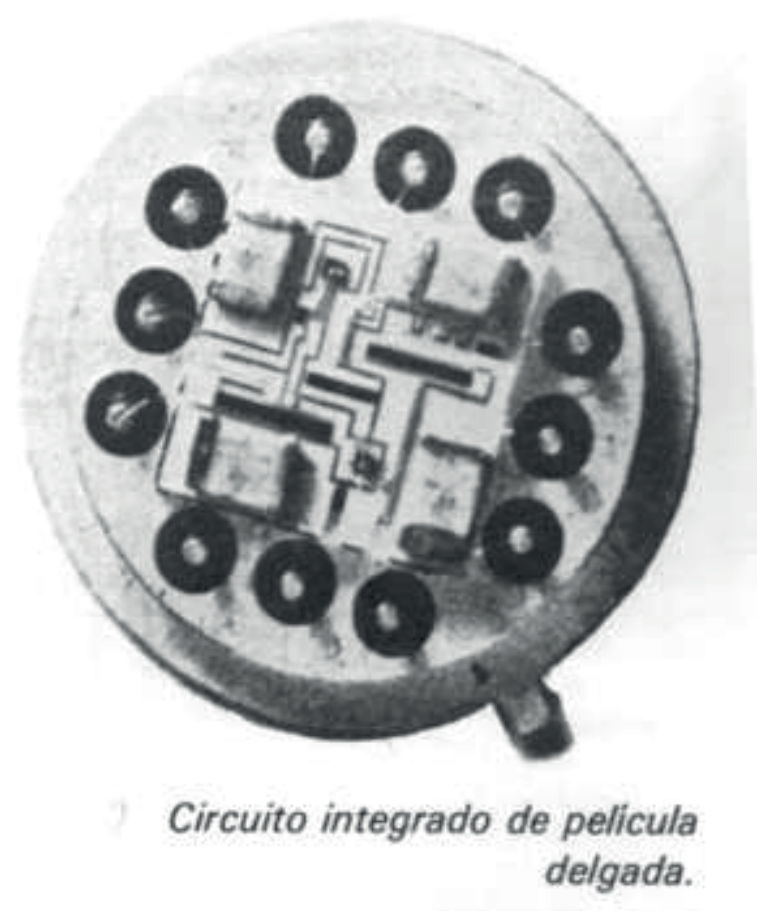

En este tipo de circuitos, las resistencias se obtienen por condensación, generalmente, de tantalio o cromo-níquel sobre áreas de geometría determinada. Los condensadores se forman a partir de dos superficies conductoras separadas por un dieléctrico, que generalmente es óxido de silicio. Los diodos y transistores son, por lo general, estructuras planares montadas sobre soportes adecuados, que se unen al circuito mediante soldadura, termocompresión o ultrasonidos. Los circuitos integrados de película delgada se emplean fundamentalmente en circuitería analógica, dada la gran precisión con la que se pueden obtener las resistencias (tolerancias inferiores $\pm 0,1 \%$ ).

Los circuitos integrados de película gruesa (thick-film) son circuitos en los que los elementos pasivos y las distintas interconexiones se forman sobre un substrato cerámico, imprimiendo, por procedimientos serigráficos, distintos tipos de pasta, la cual contiene elementos dieléctricos y conductores, que conformarán los diferentes elementos del circuito a implementar. En este tipo de circuitos los elementos activos también son incorporados como unidades independientes: 


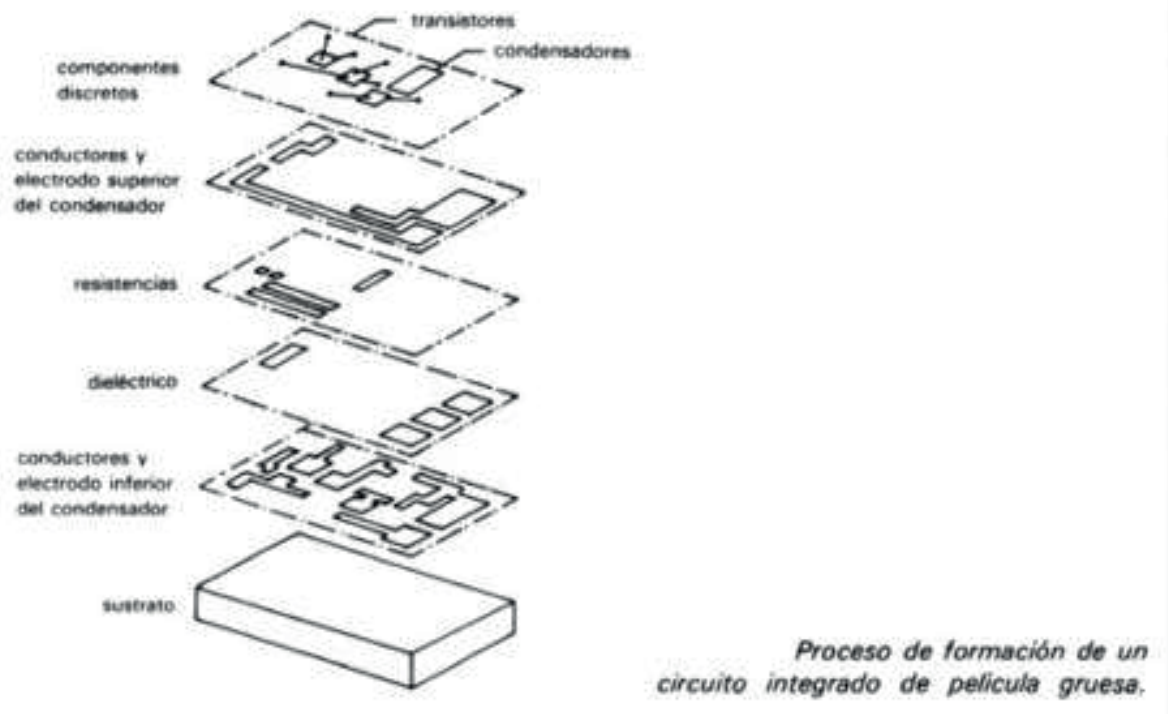

Las resistencias se forman mediante la colocación, sobre el substrato, de una pasta que contiene, sobre un vehículo disolvente, partículas de paladio y de plata. Los condensadores pueden ser de dos tipos: bien, unidades independientes que se montan como los diodos o los transistores, o bien pueden ser de tipo pelicular formados sobre el mismo substrato para valores de capacidad reducidos. Los elementos activos se interconectan al resto del circuito de manera análoga a la descrita en los circuitos integrados de película delgada: 


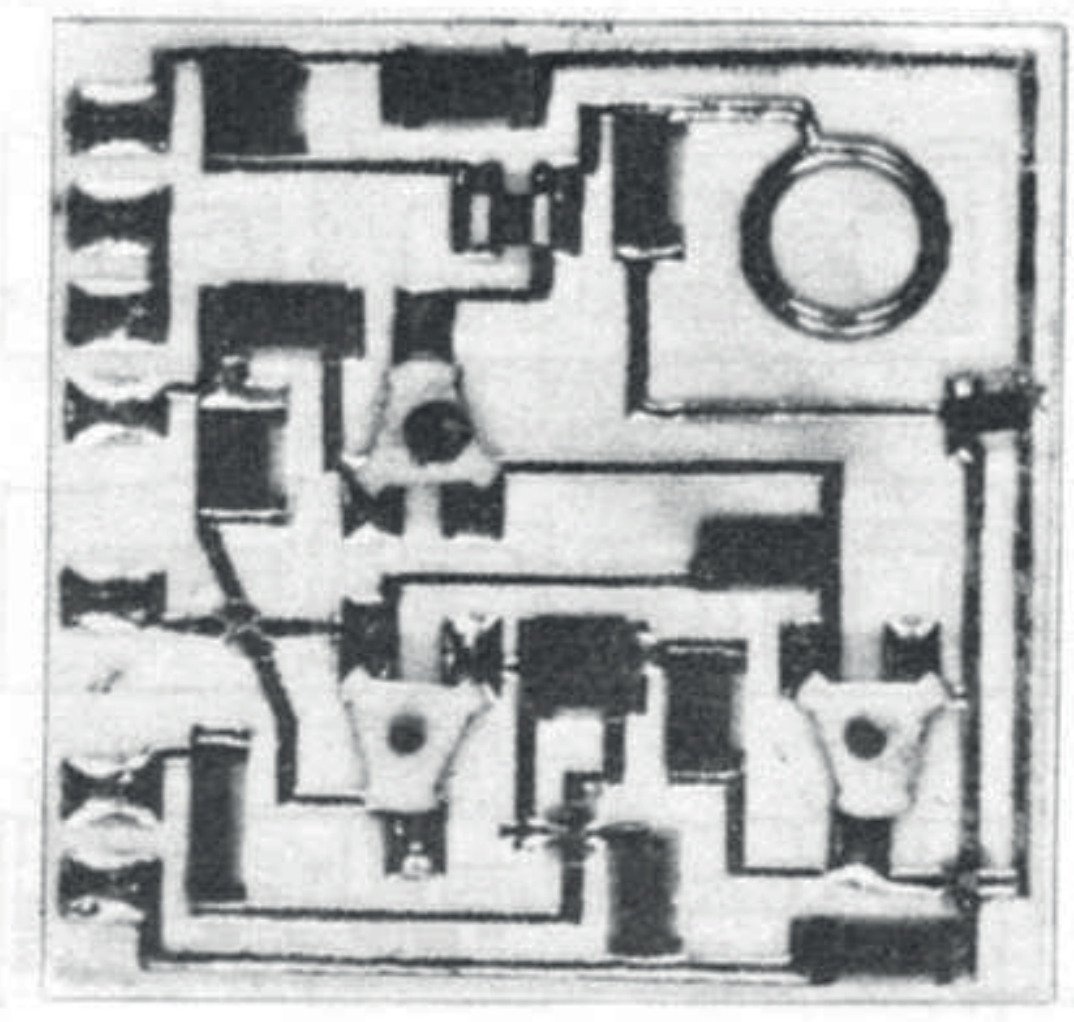

\section{Circuito integrado de pelicula gruesa.}

\section{Conclusión}

Con este artículo damos por terminada esta breve presentación de la fabricación de los elementos de la circuitería electrónica. Habrán notado que no hemos desarrollado los circuitos integrados multiplaca e híbridos. Dejamos pendiente, para una posible próxima contribución este tema, que haría innecesariamente largo este trabajo. 